\title{
O discurso de ódio contra a população LGBTQIA+ em três casos do Judiciário brasileiro
}

\section{Hate speech against the LGBTQIA+ population in three cases of the brazilian Judiciary}

Yuri Rocha Lima dos Santos ${ }^{1}$, Maria Sueli Rodrigues de Sousa ${ }^{1}$, Gabriel Eidelwein Silveira ${ }^{1 *}$

\section{RESUMO}

Analisaremos no presente trabalho o tratamento dado pelo Judiciário nacional às demandas relacionadas ao discurso de ódio, em três casos judiciais. Antes de passar à análise dos casos concretos apresentaremos as principais teorias sobre a decisão judicial tal como a teoria de Kelsen, Hart e Dworkin, analisando suas concepções sobre a decisão jurídica com vista a situar a discussão no panorama teórico atual. Ao analisar as decisões judiciais, utilizaremos a teoria discursiva do direito de Habermas para refletir sobre a importância da justificação perante a comunidade de juristas e o ordenamento.

Palavras-chave: Discurso de ódio. Decisão. População LGBTQIA+.

\begin{abstract}
In this paper, we will analyze the treatment given by the Brazilian judiciary to lawsuits related to hate speech, in three judicial cases. We will present the main theories about the judicial decision, such as the theories of Kelsen, Hart and Dworkin, analyzing their conceptions about the legal decision in order to place the discussion in the current theoretical panorama. When analyzing judicial decisions, we will use Habermas's discourse theory of law to reflect on the importance of justification before the legal community and the legal system.
\end{abstract}

Keywords: Hate speech. Decision. LGBTQIA+ population.

\section{INTRODUÇÃO}

No presente trabalho estudaremos o discurso de ódio no ordenamento pátrio tomando por base três decisões judiciais cujo mérito envolve o objeto de estudo. Em primeiro momento passamos à análise jurídica do objeto de estudo, verificando os

1 Universidade Federal do Piauí - UFPI. *E-mail: professor.gabriel@ufpi.edu.br 
argumentos contrários e favoráveis ao discurso de ódio. Analisamos a decisão judicial no aspecto dos argumentos jurídicos utilizados pelos julgadores, bem como pelos parâmetros apresentados pela teoria do discurso de fundamentação de Jürgen Habermas.

Os casos utilizados foram identificados como paradigmáticos pela notoriedade que ganharam nos meios de comunicação social e por versarem sobre a temática do discurso de ódio contra a população LGBT. Procedemos ao processamento de informações a partir da técnica de mapa analítico (framework) por meio do qual pude analisar as particularidades do discurso, sem perder de vista a compreensão do objeto em sua inteireza.

Foram três casos concretos selecionados: o inquérito 3.590/DF proposto pelo Ministério Público Federal contra o deputado Marco Antônio Feliciano, que em sua conta na rede social Twitter publicou conteúdo discriminatório contra a comunidade LGBTQIA+; o segundo caso analisado é a Ação Civil Pública proposta pelos grupos Diversidade Niterói, Cabo Free de Conscientização Homossexual e Combate à Homofobia e Grupo Arco Iris de Conscientização Homossexual contra Jair Messias Bolsonaro que no programa Custe o Que Custar (CQC), se manifestou reproduzindo discurso discriminatório e opressor contra minorias sexuais; o terceiro caso é a Ação Civil Pública (nº 1098711-29) proposta pela Defensoria Pública do Estado de São Paulo contra José Levy Fidelix da Cruz tendo em vista manifestação que incitou o ódio e discriminação contra a população LGBTQIA+.

Por meio da análise das supracitadas decisões judiciais à luz das teorias de jusfilósofos contemporâneos, objetivou-se compreender qual o posicionamento do Judiciário no momento histórico em que foram proferidas as decisões judiciais sobre o discurso de ódio contra a comunidade LGBTQIA+. Para além, visamos explicitar os argumentos utilizados pelas instituições para fundamentar suas decisões e, a partir de tal perspectiva, debater sobre a adequação ou não das mesmas à ordem constitucional vigente.

\section{2 (DES)LEGITIMIDADE DO DISCURSO DE ÓDIO}

A partir da análise das decisões judiciais, foi possível identificar dois argumentos em defesa da validade do discurso de ódio: que a liberdade de expressão protege o discurso de ódio e que o argumento é materialmente legal, ou seja, que a manifestação 
defende valores positivados no ordenamento. A partir da análise das informações contidas no mapa, é possível avaliar a validade formal e material da manifestação proferida.

Do voto proferido por Luís Roberto Barroso no inquérito 3.590/DF se extrai a seguinte passagem: “[...] a liberdade de expressão é aquela que protege os nossos adversários, é aquela que protege quem pensa diferentemente de nós.”. Note-se que se defende a liberdade de expressão no sentido da proteção dos oponentes do discurso, ficando implícito que a proteção dos interlocutores visa garantir a igualdade durante o mesmo.

O contraditório no argumento supracitado é que ao se defender o discurso de ódio como argumento válido se está defendendo o discurso não baseado na igualdade entre os participantes, elemento que rompe a coesão interna do discurso impedindo que o mesmo ocorra, pois, para haver discurso, os sujeitos têm que se inter-reconhecer como discursivamente iguais (Habermas, 2003). Tendo em vista a contradição do argumento utilizado em defesa do discurso de ódio, creio que não seja válido o argumento de que para manter a igualdade na discussão se deva defender inclusive discursos cujo mote é a desigualdade e exclusão de determinado grupo.

O segundo argumento em defesa do discurso de ódio, é que o conteúdo do mesmo está em sintonia com o ordenamento jurídico, desse modo, se argumenta por uma possível legalidade material do discurso discriminatório. É válido avaliar trecho da defesa de Levy Fidelix na Ação Civil Pública no 1098711-29: “o requerido deixou claro à população brasileira sua postura de defensor da família contemplada no artigo 1.514 do Código Civil

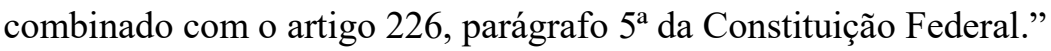

A inteligência do fragmento supracitado faz referência ao artigo 1.514 do Código Civil que, para citar a necessidade de manifestação livre dos nubentes, expressos os termos "homem" e "mulher". Já o artigo 226, parágrafo $5^{\circ}$ da Constituição Federal é citado quanto à referência à sociedade conjugal ser formada por "homem e mulher". Desse modo, o réu do processo pinçou do ordenamento apenas aquilo que lhe era pertinente, deturpando a integridade do direito (DWORKIN, 1999) e o sentido geral determinado pelo ordenamento jurídico que expressa a proteção à igualdade e dignidade humana, não fazendo sentido a exclusão da possibilidade de casamento igualitário entre pessoas do mesmo sexo. No entanto, tal deturpação por meio da fragmentação da integridade e unidade do ordenamento tem a finalidade, tão somente, de fundamentar a manifestação de ódio proferida. 
Outro argumento que invalida o discurso de ódio é o de que não existem direitos absolutos. Em manifestação do Ministério Público Federal (MPF) na Ação Civil Pública no 1098711-29, ficou assentado que "a liberdade de expressão, ainda que configure direito caro à sociedade, não é absoluta, apresentando limites constitucionais quando implica em violações a direitos fundamentais do homem", tal pensamento foi ratificado na Ação Civil Pública 0115411-06, na qual se afirma que o Código Civil proíbe o abuso de direito (artigo 187 do Código Civil). Ainda segundo o MPF, não se trata sequer de discutir se absoluto ou relativo o princípio da liberdade no caso de discurso de ódio, uma vez que o único princípio violado é o da dignidade humana, posto que inobservado quando da manifestação de ódio por parte dos réus.

Fazendo um esforço, é possível distinguir entre pretensa manifestação de legalidade formal e material. A validade formal que se pretende do discurso de ódio decorreria apenas da sua forma, ou seja, em razão de ser um argumento que teria legitimidade discursiva em razão da proteção garantida pela liberdade de expressão. Já a pretensão de validade baseada na materialidade da manifestação diz respeito ao conteúdo da mesma que seria válida por defender valores protegidos por lei. Porém, ambas hipóteses de validade do discurso de ódio são inócuas tendo em vista que o ordenamento jurídico pátrio ao citar um tipo de união conjugal (no caso a heteronormativa formada por homem e mulher cisgênero), não exclui as demais formas de união. No mesmo sentido, o sistema jurídico pátrio não admite que seja desconsiderada a dignidade do sujeito, em função de qualquer característica individual que o distinga dos demais.

Tendo em vista o discutido até esse momento, não é possível a defesa da validade formal ou material da manifestação de ódio. Como já exposto em outro momento, o discurso de ódio não é argumento válido para o discurso em razão de negar igualdade discursiva ao interlocutor. No mesmo sentido, não é possível a defesa da pretensão de validade material, haja vista que o ordenamento em sua inteireza não comporta desigualdade, preconceito ou a concepção de seres humanos de "segunda classe", mas sim a igualdade constitucional.

\section{DISCURSO DE ÓDIO E “AUSÊNCIA” DE LEGISLAÇÃO}

Tanto no processo decisório quanto na repercussão pública quanto à condenação do discurso de ódio, foi questionado até que ponto a legislação penal daria conta de tal 
tema e se sim, em qual medida. Por tal motivo, refletiremos sobre a necessidade de norma que fundamente a condenação penal, bem como o tipo penal que disciplina tal conduta. Em outro momento, será analisada a pretensão de punição em âmbito cível.

Um dos argumentos levantados a favor da condenação em âmbito penal do deputado Marco Feliciano baseava-se em interpretação extensiva da norma prevista no artigo 20 da lei 7.716/89, que apresenta um rol taxativo de condutas consideradas discriminatórias para fins de punição penal, a saber, discriminação por raça, cor, etnia,religião ou procedência nacional. É patente que o ordenamento jurídico concretiza consenso social de que não é admissível a discriminação de qualquer natureza, denota tal entendimento os inúmeros dispositivos legais que preveem a proibição e, muitas das vezes, punição daqueles que praticam ato discriminatório.

No entanto, o entendimento à época defendido pelos ministros e ministras do Supremo Tribunal Federal foi pela impossibilidade de punição penal sem lei prévia que a determine, não podendo haver analogia entre situações expressamente previstas na lei penal e aquelas que guardam ponto de contato com as mesmas.

Em âmbito cível, é possível notar, na fundamentação das decisões dos magistrados, o consenso existente quanto à vedação ao abuso de direito, bem como a primazia do princípio da dignidade humana dentro do ordenamento jurídico nacional. Vale ressaltar que os órgãos do Judiciário, conseguiram perceber as entrelinhas do discurso de ódio, que se apresentou, por vezes, camuflado entre palavras que tentavam deturpar o verdadeiro conteúdo e intenção da manifestação.

Quanto à manifestação do magistrado, é válido citar passagem em que este órgão analisa o conteúdo da fala de Jair Bolsonaro:

Expressou publicamente suas ideias de que a orientação homossexual é resultante da falta de educação, caracterizando maus costumes, incompatíveis com crença em Deus e com a preservação da entidade familiar, podendo conduzir à ruína da nação. Sugeriu, ainda, que homossexuais poderiam votar em um heterossexual por reconhecimento à sua superioridade. [...] Dúvida, assim, não existe quanto ao cunho agressivo das declarações do réu, que tiveram o claro propósito de humilhar e diminuir todo um segmento social.

Tendo em vista o fragmento supracitado, nota-se que o magistrado identificou os elementos do discurso de ódio. É possível citar a atribuição de características pejorativas, bem como a tentativa de associação entre o grupo-alvo e a extinção da ordem social estabelecida, transmitindo a ideia de subversão social. Para além disso, é explícita a defesa de suposta superioridade entre heterossexuais e a comunidade LGBTQIA+. Outra 
característica citada é que a manifestação teve por finalidade "humilhar e diminuir todo um segmento social", daí que é marcado o tom de tentativa de segregação do grupo-alvo em face da sociedade.

Importante notar, a partir da análise até aqui desenvolvida, que no momento histórico em que ocorreram tais decisões judiciais, imperava no Judiciário o entendimento de que não havendo a elaboração de uma lei específica que tornasse criminosa a ação socialmente danosa do discurso de ódio, tal ação só seria passível de punições na seara civil. Porém, já era corrente na comunidade jurídica e, consequentemente, já começava a adentrar às instituições judiciais, a ideia de que não poderia o Judiciário se furtar a tutelar bens como dignidade e igualdade sob o argumento de ausência de legislação.

\section{BREVE HISTÓRICO DA TEORIA DA DECISÃO JUDICIAL}

Visando adensar a discussão, nos propomos a analisar os casos sob a ótica das teorias da decisão judicial. Para tanto, faz-se necessário um panorama sobre as principais perspectivas sobre o tema, visando compreender as aproximações e distanciamentos entre as mesmas. Discorreremos brevemente sobre as teorias de Kelsen, Hart, Dworkin e Habermas, analisando suas concepções sobre a decisão jurídica.

De acordo com Habermas (2003), o processo de decisão apresenta indeterminação que precisa ser adensada e transformada em concretude, garantido segurança jurídica. Para tanto, é necessário que a fundamentação da decisão judicial apresente dois requisitos: que se baseie no consenso de todos os "parceiros do direito" e que crie a norma para o caso concreto - decisão - dentro dos parâmetros impostos pela comunidade jurídica. Nas palavras do teórico:

[...] a pré-compreensão pragmática do direito em geral só pode colocar limites à indeterminação do processo de decisão iniciado teoricamente e garantir uma medida suficiente de segurança jurídica, se for compartilhada intersubjetivamente por todos os parceiros do direito e se expressar uma autocompreensão constitutiva para a identidade da comunidade jurídica. (HABERMAS, 2003, p. 278)

Outra categoria apresentada por Habermas (2003) é a de "bom argumento", segundo o filósofo, o bom argumento é aquele que na discussão sobre questão controversa se resgata uma "pretensão" de validade estabelecida previamente pelo consenso. Desse modo, apenas é considerado bom argumento aquele que se baseia no direito, uma vez que o mesmo é a materialização dos consensos preestabelecidos para solucionar questão 
controversa que se apresente ao Judiciário. Ficam excluídos argumentos esdrúxulos ou desconexos com o sistema preexistente.

Antes de prosseguir com o pensamento de Habermas, faz-se necessária análise da evolução da teoria da decisão judicial. Em sentido diverso ao apresentado por Habermas, Kelsen (1998), jusfilósofo positivista, compreende que a decisão coincide com a norma. No escalonamento de legitimidade das normas existe a norma fundamental, que legitima todo o ordenamento jurídico, existindo, em patamar inferior, diversos tipos normativos, sempre obedecendo à hierarquia de validade. Há ainda a norma para o caso individual que é a decisão judicial. Como assevera o teórico:

Todo ato criador de Direito deve ser um ato aplicador de Direito, quer dizer: deve ser a aplicação de uma norma jurídica preexistente ao ato, para poder valer como ato da comunidade jurídica. (KELSEN, 1998, p. 164)

Ainda vinculado à ideia positivista de direito, Hart (1994), dá um passo adiante em relação à teoria da decisão judicial, pois, segundo o jusfilósofo, a aplicação do direito envolve criação, pelo intérprete, mas limitação do mesmo pelo direito legislado, desse modo, o ordenamento legitima determinados órgãos a dizerem o que é o ordenamento.

Não deve soar estranha a noção de decisão como via de mão dupla, uma vez que conforma o ordenamento e é conformada por ele, em virtude da impossibilidade de exaurimento da previsão de todas as situações fáticas que surjam na sociedade (HART, 1994, p. 166).

Ainda segundo Hart (1994), existem casos complexos em que, não importando se se pretende a aplicação do direito legislado ou dos precedentes, sempre haverá margem de indeterminação na aplicação da lei ao caso concreto, nas palavras do autor:

para a comunicação de padrões de comportamento, estes, não obstante a facilidade com que atuam sobre a grande massa de casos correntes, revelar-se-ão como indeterminados em certo ponto em que a sua aplicação esteja em questão; possuirão aquilo que foi designado como textura aberta (HART, 1994, p. 140 e 141).

A solução para a "textura aberta" do direito, na ausência de outra saída proveniente do legislativo, o juiz "deve exercer seu poder discricionário e criar direito para o caso, em vez de aplicar meramente o direito estabelecido preexistente" (HART, 1994, p. 335).

Por outro lado, Dworkin (2007) também reflete sobre a imprecisão na aplicação do direito ao caso concreto. De acordo com o jusfilósofo, muitas vezes o direito é “obscuro", há imprecisão na linguagem ou no sentido da lei que, aparentemente, incide 
no caso concreto. Porém, para solucionar a imprecisão do ordenamento, o teórico americano estabelece que o juiz se valha dos princípios do direito, não de fontes externas ao direito como pretendia Hart com a discricionariedade, apresentando resposta para a falha ou omissão do ordenamento com o próprio ordenamento.

Desenvolvendo o seu método de decisão, Dworkin (2007) propõe a ideia de interpretação criativa que busca a intenção do texto legal, não devendo se confundir com a busca da intenção do legislador. Para tanto, o juiz "Hércules" deve fazer o máximo de esforço para tentar analisar todos os desdobramentos morais e jurídicos envolvidos no caso para que, só então, consiga encontrar uma única resposta correta.

Retomando o pensamento de Habermas (2003), o discurso de aplicação do direito não comporta valorações morais nem do caso concreto nem da norma. Para uma decisão judicial adequada, é necessário que o juiz lance mão apenas dos consensos já positivados em lei, uma vez que estes delimitam a área interpretativa na qual o julgador atuará. Desse modo, não é possível uma interpretação baseada na razão prática, vinculada à moral, mas sim em uma racionalidade discursiva que parte do pressuposto que os princípios, que possuem conteúdo moral e são direito positivado, não cabendo ao intérprete recorrer a outras fontes para a interpretação e aplicação da lei, uma vez que o próprio ordenamento fornece meios para tanto (BRASIL, 2000).

Por meio da exposição das teorias, pretendemos delimitar o foco de análise que será dado a partir desse momento na compreensão do modo como se forma a convicção do juiz, bem como da aplicação da lei ao caso concreto. Pelos modelos teóricos supracitados, convencional, pragmático, direito como integridade e racionalidade discursiva, é possível determinar que uma boa decisão seja aquela que guarda vínculo com a norma e com o ordenamento, não no sentido positivista de aplicação mecânica da lei por um juiz que seja "a boca da lei", nem de um juiz que "cria o direito", mas no sentido de não ser negada a vinculação do julgador aos valores da comunidade, princípios positivados no ordenamento jurídico, balizando a decisão mesmo nos casos em que a norma aparente ser imprecisa.

5 A NORMA PARA O CASO CONCRETO: O DISCURSO DE APLICAÇÃO DE HABERMAS 
Discorrido sobre as diferentes correntes de pensamento da teoria da decisão judicial, focaremos a teoria de fundamentação de Habermas (2003). Segundo tal teoria, tanto o ordenamento jurídico quanto o Estado adquirem legitimidade a partir do processo discursivo democrático de inclusão e participação da sociedade na formação de consensos que serão positivados no ordenamento jurídico. Porém, como é evidente, tal teoria é voltada ao legislativo. Para o Judiciário, Habermas idealiza o discurso de aplicação que consiste na integração de fatores jurídicos e políticos factíveis e preestabelecidos pelo legislador no ordenamento jurídico visando à elaboração da norma para o caso concreto, a decisão.

Habermas propõe que o discurso de aplicação (jurisdição) se diferencia em muitos pontos do discurso de justificação (legislação). Primeiramente, há diferenças nos tipos de linguagem empregadas em cada tipo de discurso. No discurso de justificação é necessário o agir comunicativo que, por meio do diálogo entre participantes que se pressupõem iguais, atribui legitimidade à legalidade (CRUZ, 2008). Já o discurso de aplicação não se vale do agir comunicativo para garantir sua legitimidade, uma vez que a adquire em razão do uso de normas prévia e presumidamente legítimas. Do mesmo modo se dá com relação à facticidade, que é integrada ao discurso de aplicação por ter sido incluída previamente na norma pelo processo legislativo.

Outro ponto de diferenciação entre discurso de justificação e de aplicação é que no primeiro o diálogo entre as partes se dá de modo "livre" só havendo coordenação por meio do pressuposto da igualdade entre os participantes do debate e da busca da verdade (consenso). No discurso de aplicação não é possível contar a cooperação entre as partes envolvidas em virtude de pleitearem benefício para si, muitas vezes em detrimento do interesse da outra parte, desse modo, o pressuposto da busca da verdade estaria prejudicado. Visando então a formação de um consenso imparcial, o processo judicial passa a balizar o diálogo entre as partes garantindo interação entre as mesmas, por meio dos procedimentos processuais estabelecidos, por mais que estejam interessadas em benefícios individuais.

Ademais, enquanto que no discurso de justificação qualquer argumento ético/moral é válido no debate, no discurso de aplicação só é possível o uso de argumentos ético/morais que estejam positivados no ordenamento jurídico. Em última análise, se um argumento ético/moral foi incluído no ordenamento jurídico por um processo legislativo que lhe atribui legitimidade, então não se trata mais de argumento ético/moral e sim de 
direito. Desse modo, a diferença entre as duas formas de argumentação reside no fato de que no discurso de justificação os argumentos são ético/morais, havendo maior "liberdade" na escolha e uso dos mesmos, ao passo que no discurso de aplicação os argumentos são necessariamente jurídicos, havendo restrição da gama de possibilidades argumentativas tendo em vista que só é possível o uso daquilo que é permitido pelo ordenamento jurídico.

Dutra (2006) defende que a restrição ao universo argumentativo imposto pelo direito e consequente seleção dos argumentos passíveis de serem invocados no Judiciário garante obediência tanto à divisão de poderes quanto à segurança jurídica. A separação de poderes é garantida em virtude de se considerar o consenso positivado por meio democrático pelo Legislativo, não se criando no Judiciário direito diverso daquele legislado. Já a segurança jurídica é assegurada em virtude da certeza de aplicação ao caso concreto da lei resultante do consenso político e não de nenhum argumento moral, ético ou pragmático que porventura fosse arbitrado pelo juiz.

Outro conceito relevante da teoria de Habermas é o de correção. Segundo o teórico, a correção não é apenas a correspondência entre direito e fatos e sim "o preenchimento de condições comunicativas da argumentação, que tornam possível uma formação imparcial do juízo.” (HABERMAS, 2003, p. 287). Desse modo, é necessário que exista o preenchimento de requisitos processuais que visem à manutenção da imparcialidade dos juízos criando barreira protetiva contra o "agir estratégico" das partes.

Para garantir a formação de um juízo imparcial o ordenamento jurídico estabelece normas, via de regra, de natureza processual, que determinam o "passo-a-passo" a ser seguido pelas partes de um processo judicial. Dutra (2006) identifica, no ordenamento brasileiro, as principais normas que se prestam a garantir a imparcialidade do juízo sobre o conflito levado ao Judiciário:

- a Constituição da República Federativa do Brasil, em seu art. 5o, LIV, estabelece que "ninguém será privado da liberdade ou de seus bens sem o devido processo legal"; no inciso LV, estatui como direito individual o contraditório e a ampla defesa, e no art. 93, III, ordena que todas as decisões judiciais sejam fundamentadas, sob pena de nulidade; - o CPP, no art. 157, preceitua: "O juiz formará sua convicção pela livre apreciação da prova". O art. 381, III, estabelece que a sentença deve conter "a indicação dos motivos de fato e de direito em que se funda a decisão"; - o CPC esculpiu no art. 131: "O juiz apreciará livremente a prova, atendendo aos fatos e circunstâncias constantes dos autos, ainda que não alegados pelas partes; mas deverá indicar, na sentença, os motivos que lhe formaram o convencimento". No art. 192, preceitua que os prazos peremptórios não podem ser reduzidos ou prorrogados pelas partes. $\mathrm{O}$ art. 286 ordena que o pedido deve ser certo ou 
determinado, estabelecendo os casos em que o mesmo pode ser genérico. $\mathrm{O}$ art. $331, \S 20$, estatui que, não obtida a conciliação no processo, "o juiz fixará os pontos controvertidos, decidirá as questões processuais pendentes e determinará as provas a serem produzidas" (DUTRA, 2006, p. 29 e 30).

Por meio da análise dos dispositivos citados acima é possível identificar que o direito ao processo estabelecido pelo ordenamento (devido processo legal), a livre apreciação de provas, a obrigatoriedade de justificação da decisão, bem como a impossibilidade de regulação de prazos pelas partes são requisitos processuais essenciais à formação do juízo imparcial. Apesar da utilidade de adotar um procedimento legal para a verificação concreta da correção nos casos jurídicos, abro mão de fazê-lo no presente momento, em razão do objetivo primordial desse estudo bem como pela exiguidade do tempo, ficando para estudo posterior o aprimoramento e utilização do procedimento adotado por Dutra (2006) para verificar a correção das decisões.

Outro requisito que será analisado nas sentenças judiciais é a utilização de argumentos jurídicos e não de argumentos éticos, morais ou pragmáticos pelo juiz quando da decisão judicial. Em suma, tentarei verificar a correspondência entre a teoria do discurso de aplicação de Habermas e as sentenças estudadas.

Passando ao conteúdo das decisões judiciais, no inquérito no 3590 DF, julgado pelo STF, o ministro Luís Roberto Barroso, mestre pela Yale Law School, se pronunciou "penso também que a liberdade de expressão não existe para proteger apenas aquilo que seja humanista, aquilo que seja de bom gosto ou aquilo que seja inspirado.”. Na fala do ministro não é possível identificar que esteja apreciando prova, mas sim que está fundamentando seu entendimento.

Quando o ministro afirma que a liberdade de expressão protege inclusive o que não é de "bom gosto" ou que não é "inspirado" reitera consenso existente de que não é possível censura sob o argumento de determinada manifestação ser de mau gosto ou de não ser "inspirada", uma vez que tal avaliação é subjetiva, varia de indivíduo para indivíduo, nesse momento a justificação do voto se alinha ao previsto no artigo $220, \S 2^{\circ}$, da CRFB, que estabelece ser "[...] vedada toda e qualquer censura de natureza política, ideológica e artística.". Tendo em vista tal fato, é possível defender a correspondência entre a manifestação do ministro e a Lei Maior que estabelece a impossibilidade de cerceamento de manifestação de pensamento em virtude de desacordo com determinada corrente ideológica, política ou padrão artístico. 
No entanto, quando o Ministro Barroso afirma que a liberdade de expressão protege inclusive o que não é "humanista" aparenta haver dissonância entre o ordenamento brasileiro e a posição defendida pelo ministro. $\mathrm{O}$ sentido vernacular do termo "humanista", segundo o Dicionário da Academia Brasileira de Letras, é aquilo que é "relativo a humanismo", sendo que "humanismo" significa, segundo o mesmo dicionário, "valorização do homem e do que é humano". Ora, não é cabível defender a legalidade de manifestação que desvalorize o ser humano e aquilo que lhe for inerente em um ordenamento em que a dignidade humana, previsto no art. 1o, III, da CRFB, é eleita como princípio que fundamenta o estado Brasileiro.

Ainda tratando do inquérito 3590/DF, movido contra Marco Feliciano, o ministro Marco Aurélio entende que "o denunciado teria publicado, em sítio da internet, o seguinte trecho: 'A podridão dos sentimentos dos homoafetivos levam (sic) ao ódio, ao crime, à rejeição.' A expressão seria suficiente para atrair a incidência do disposto no artigo 20 da Lei no 7.716/89 [...]". O artigo citado prevê pena para todo aquele que "Praticar, induzir ou incitar a discriminação ou preconceito de raça, cor, etnia, religião ou procedência nacional.", a partir da lei e do ordenamento o ministro extrai a norma que veda a discriminação e o preconceito, daí que afirma ser cabível a adequação do caso à norma penal invocada. Desse modo, há adequação do discurso utilizado na fundamentação do voto aos argumentos positivados no ordenamento jurídico.

Porém, na continuidade de seu voto, afirma a impossibilidade de estender a punição expressa no artigo 20 da lei 7716/98, à conduta de discriminação em razão da orientação sexual, em virtude da lei penal em questão ser taxativa nos casos em que incide e por não fazer menção a esse tipo de discriminação/preconceito. Cita o art. $5^{\circ}$, XXXIX da CRFB que prevê a inexistência do crime sem lei anterior que o defina. Tal manifestação demonstra mais uma vez adequação entre decisão e ordenamento jurídico.

Ainda segundo Habermas (2003), o juiz não realiza o esforço interpretativo apenas com livros e textos, distante da sociedade e dos seus pares, é necessário que fundamente sua decisão para a comunidade de juristas, que expresse o consenso jurídico existente sobre determinada questão. É isso que o ministro Barroso faz ao se manifestar no sentido de que uma decisão que fosse de encontro ao princípio nullum crimen, nulla poena "vulneraria princípios que nós consideramos importantes". Quando se diz "nós" o ministro está se referindo à comunidade de juristas, confirmando que o princípio em questão é um consenso da comunidade, já positivado em lei, que baliza a decisão judicial. 
Passando à análise da Ação Civil Pública impetrada contra Jair Bolsonaro, o juiz em sua decisão analisa o discurso de ódio proferido pelo réu e conclui que é inequívoco o "cunho agressivo das declarações do réu, que tiveram o claro propósito de humilhar e diminuir todo um segmento social.”. A partir do fragmento é possível deduzir que o juiz quando da interpretação da lei e aplicação ao caso concreto levou em consideração o consenso social sobre valores como igualdade e dignidade humana, daí deduzindo que a manifestação não se enquadra como simples expressão de opinião e sim como meio de opressão e exclusão de determinado grupo social.

A justificação in abstrato perante a comunidade de juristas é necessária para que seja reduzida a indeterminação inicial do processo, bem como para que se alcance um mínimo de segurança jurídica (HABERMAS, 2003). A partir da leitura das decisões é possível deduzir que o juiz procede à interpretação da manifestação do réu considerada agressiva demonstrando que o conteúdo da mesma é reprovável. Daí que nesse primeiro momento o juiz delimita em que sentido conduzirá sua decisão, reduzindo a indeterminação da decisão judicial e atribuindo à mesma um mínimo de segurança jurídica. Por outro lado, o julgador mostra-se uníssono com o consenso de que manifestações no sentido de "humilhar e diminuir" não são legítimas.

Ainda sobre a Ação Civil Pública impetrada contra Jair Bolsonaro, é relevante refletir sobre o fragmento paradigmático da decisão: “A ilicitude do réu não decorre de suas ideias, mas da forma como optou por expressá-las publicamente em inobservância ao direito de todo um grupo social à vida digna.”. Nesse ponto o Juiz demonstra que não é ilícito nem punível o ato de pensar, tendo em vista que só interessa ao direito aquilo que se manifeste no mundo dos fatos de modo a prejudicar direito de terceiro, como bem lembra o julgador na parte final do fragmento em análise.

Em terceiro momento da justificação de seu voto, o julgador do caso Bolsonaro invoca a vedação ao abuso de direito imposto pelo artigo 187 do Código Civil, afastando o argumento de que o discurso de ódio é amparado pelo direito à liberdade de expressão. No princípio da dignidade humana, positivado no art. $1^{\circ}$ da CRFB, encontra-se a justificativa para a proteção dos grupos-alvo de discriminação e opressão. Prosseguindo, o juiz do caso em análise defende que a Constituição da República rechaça a discriminação (art. $3^{\circ}$ da CRFB) e desigualdade (art. $5^{\circ}$ da CRFB).

Tendo em vista o exposto, bem como a teoria do discurso de aplicação, é possível avaliar a decisão em questão como adequada ao ordenamento jurídico pátrio e aos 
requisitos argumentativos da decisão judicial. Passando à análise da decisão da Ação Civil Pública impetrada contra Levy Fidelix, é possível identificar as mesmas fases de justificação que a decisão analisada anteriormente. Inicialmente o juiz reduz a incerteza processual delimitando em que sentido julgará, bem como utilizando o consenso da classe dos juristas para dar um mínimo de segurança jurídica à decisão judicial, ato contínuo, passa a fundamentar juridicamente sua decisão citando o princípio da dignidade humana, da igualdade e da vedação ao abuso de direito.

Por todo o exposto, é possível avaliar que, de um modo geral, as decisões judiciais se adéquam ao que prescreve a teoria da justificação da decisão judicial. A partir do momento em que o juiz não se distancia do ordenamento jurídico para embasar sua decisão fica demonstrado que utiliza o consenso positivado no ordenamento jurídico, não se valendo de argumentos morais, éticos ou pragmáticos. Em outro ponto, o juiz, que integra a sociedade e faz parte da construção de consensos sociais, fundamenta inicialmente sua decisão em consonância com o entendimento dos "parceiros do direito", ato que, ao mesmo tempo, reduz a indeterminação do processo judicial e garante segurança jurídica à decisão que começa a tomar forma.

\section{CONSIDERAÇÕES FINAIS}

Por todo o exposto, foi observado que os juízes, ao proferirem seu voto, demonstram repúdio às manifestações de ódio, revelando que o consenso da classe de juristas é pela deslegitimidade do discurso de ódio. Quando instado a decidir pela punição em âmbito penal daqueles que se manifestam oprimindo ou incentivando a opressão de determinado grupo, no STF manteve-se o entendimento de não ser possível penalização de ato não tipificado em lei prévia ao mesmo. Tal posicionamento é localizado no momento histórico em que são proferidas as decisões.

Com relação à fundamentação das decisões desfavoráveis às manifestações de ódio, os magistrados citaram o princípio da dignidade humana, positivado no art. $1^{\circ} \mathrm{da}$ CRFB, a vedação à discriminação (art. $3^{\mathrm{a}}$ da CRFB), à desigualdade (art. $5^{\circ}$ da CRFB) e ao abuso de direito (art. 187 do Código Civil). Desse modo, ficou demonstrado nas decisões que o posicionamento dos magistrados, pela ilegalidade do discurso de ódio, é conforme o ordenamento jurídico, característica que atribui validade ao conteúdo da decisão. 
Em suma, constatamos que nas três decisões judiciais, desfavoráveis àqueles que proferiram discurso de ódio, os julgadores apresentam decisão em consonância com o ordenamento pátrio, atendendo aos requisitos da teoria do discurso de Jürgen Habermas.

\section{REFERÊNCIAS}

BRASIL, Deilton Ribeiro. Como Compreender em Jürgen Habermas a Hermenêutica Jurídica em uma Nova Ordem Social. Universo Jurídico, Juiz de Fora, ano XI, 05 de setembro de 2000. Disponível em:

<http://uj.novaprolink.com.br/doutrina/394/como_compreender_em_jurgen_habermas_ a_hermeneutica_juridica_em_uma_nova_ordem_social $>$. Acesso em: $11 \mathrm{de}$ dez. De 2015.

CRUZ, Álvaro. Habermas e o Direito Brasileiro. Rio de Janeiro: Lumen Juris, 2008.

DWORKIN, Ronald. O Império do Direito. São Paulo: Martins Fontes, 1999.

HABERMAS, Jürgen. Direito e Democracia: entre facticidade e validade, vol. I. Rio de Janeiro: Tempo Brasileiro, 2003.

Brasileiro, 2013.

Consciência Moral e Agir Comunicativo. Rio de Janeiro: Tempo

Direito e Democracia: entre facticidade e validade, vol. II. Rio de Janeiro: Tempo Brasileiro, 2003.

HART, H. L. A. O Conceito de Direito. Lisboa: Fundação Calouste Gulbenkian, 1994.

KELSEN, Hans. Teoria pura do direito. São Paulo: Martins Fontes, 1998. 